\title{
Exhalation pattern changes during fasting and low dose glucose treatment in rats
}

\author{
Tobias Fink $^{1}$ - Frederic W. Albrecht ${ }^{1} \cdot$ Felix Maurer $^{1}$ - Astrid Kleber ${ }^{1}$ Tobias Hüppe ${ }^{1}$. \\ Kristina Schnauber ${ }^{1}$ - Beate Wolf ${ }^{1}$ - Jörg I. Baumbach ${ }^{2}$ - Thomas Volk ${ }^{1}$. \\ Sascha Kreuer ${ }^{1}$
}

Received: 11 November 2014 / Revised: 12 February 2015 / Accepted: 26 February 2015 / Published online: 26 March 2015

(C) Springer-Verlag Berlin Heidelberg 2015

\begin{abstract}
The analysis of exhaled metabolites has become a promising field of research in recent decades. Several volatile organic compounds reflecting metabolic disturbance and nutrition status have even been reported. These are particularly important for long-term measurements, as needed in medical research for detection of disease progression and therapeutic efficacy. In this context, it has become urgent to investigate the effect of fasting and glucose treatment for breath analysis. In the present study, we used a model of ventilated rats that fasted for $12 \mathrm{~h}$ prior to the experiment. Ten rats per group were randomly assigned for continuous intravenous infusion without glucose or an infusion including $25 \mathrm{mg}$ glucose per $100 \mathrm{~g}$ per hour during an observation period of $12 \mathrm{~h}$. Exhaled gas was analysed using multicapillary column ion-mobility spectrometry. Analytes were identified by the BS-MCC/IMS database (version 1209; B \& S Analytik, Dortmund, Germany). Glucose infusion led to a significant increase in blood glucose levels ( $p<0.05$ at $4 \mathrm{~h}$ and thereafter) and cardiac output $(p<0.05$ at $4 \mathrm{~h}$ and thereafter). During the observation period, 39 peaks were found collectively. There were significant differences between groups in the concentration of ten volatile organic compounds: $p<0.001$ at $4 \mathrm{~h}$ and thereafter for isoprene, cyclohexanone, acetone, $p$-cymol, 2-hexanone, phenylacetylene, and one unknown compound, and $p<0.001$ at $8 \mathrm{~h}$ and thereafter for 1-pentanol, 1-propanol,
\end{abstract}

Tobias Fink

tobias.fink@uks.eu

1 Department of Anaesthesiology, Intensive Care and Pain Therapy, Saarland University Medical Center, Kirrbergerstraße, 66421 Homburg, Saar, Germany

2 Faculty of Applied Chemistry, Reutlingen University, Alteburgstrasse 150, 72762 Reutlingen, Germany and 2-heptanol. Our results indicate that for long-term measurement, fasting and the withholding of glucose could contribute to changes of volatile metabolites in exhaled air.

Keywords Multicapillary column ion-mobility spectrometry • Volatile organic compounds · Fasting · Glucose · Long-term measurement

\section{Introduction}

The analysis of breath is a promising field of research. The presence or change of specific metabolites in exhaled air, commonly known as volatile organic compounds (VOCs), is associated with metabolic disturbance and nutritional status of the body $[1,2]$.

One approach for breath analysis is multicapillary column (MCC) ion-mobility spectrometry (IMS). It features noninvasive and rapid detection of VOCs in breath. Currently, MCC-IMS is commonly used for detection of chemical warfare agents, illegal drugs, and explosives [3-6]. But quite recently, IMS has been applied in the area of medical research $[1,7]$.

Not surprisingly, the bulk of medical research is associated with pulmonary disorders - for example, chronic obstructive pulmonary disease, asthma, cystic fibrosis, and lung cancer [8-10]. Furthermore, MCC-IMS has been used for detection of sepsis, inflammation, and various bacterial species $[11,12]$.

Thus, some VOCs have been used as characteristic markers of metabolic and pathophysiological processes: acetone and the influence of diet and diabetes, ammonia confirmed as an indicator of dialysis efficacy, isoprene as a by-product of cholesterol biosynthesis, and hydrogen cyanide released for Pseudomonas aeruginosa and cystic fibrosis [13-16].

Recent data suggest the feasibility of IMS measurement up to $24 \mathrm{~h}$ in a model of ventilated rats [17]. The long-term measurement of exhaled breath offers a variety of possibilities for the 
detection of disease progression and therapeutic efficacy. Therefore, long-term measurement is of extraordinary interest for the investigation of diseases with serious distribution and/or the need of ventilation - for example, sepsis, inflammation, pneumonia, acute lung injury, and ventilator-associated lung damage.

Especially for long-term measurement, a high degree of standardization is of utmost importance. Gender, age, time of day, and most notably feeding conditions can interfere with the concentrations and appearance of VOCs. Moreover, it is recognized that the diet and nutritional status can seriously influence the concentrations of VOCs in exhaled air, most certainly the level of acetone, ammonia, ethanol, and methanol [18-20].

In this context, it has become urgently necessary to investigate the effect of fasting and energy self-sufficiency on VOC profiles. In our current study, we used a rodent model of ventilated rats that fasted for $12 \mathrm{~h}$ prior to the experiment. For IMS breath analysis, rats were randomly assigned to receive continuous intravenous infusion without or with glucose $(25 \mathrm{mg} / \mathrm{kg} / \mathrm{h})$ during an observation period of $12 \mathrm{~h}$.

\section{Materials and methods}

\section{Animals}

The experiments were conducted in accordance with the German legislation on the protection of animals (Landesamt für Soziales, Gesundheit und Verbraucherschutz, Saarbrücken, Germany) and the National Institutes of Health guidelines for animal care. Adult male Sprague Dawley rats weighing 200-300 g were obtained from Charles River (Sulzfeld, Germany) and were kept in the institutional animal facility under controlled conditions $\left(20 \pm 2{ }^{\circ} \mathrm{C}\right.$ and $50 \pm 5 \%$ humidity). Rats had free access to water; standard pellet food was withheld for $12 \mathrm{~h}$ prior to the experiment.

\section{Animal preparation}

Surgical procedures were performed as described previously $[1,17]$. Anaesthesia was induced by intraperitoneal administration of pentobarbital at $60 \mathrm{mg} / \mathrm{kg}$. Rats were positioned on a warming plate; a tracheotomy was performed to facilitate breathing. One fluid-filled polyethylene catheter was placed in the right jugular vein to allow infusions as described below; another was inserted in the left femoral artery and connected to a pressure transducer (PowerLab 8/35, LabChart V7, ADInstruments Oxford, UK) for blood sampling, and continuous measurement of the mean arterial pressure and heart rate. The left carotid artery was catheterized to allow measurement of cardiac output using the transpulmonary thermodilution technique (MLT 1405 T-type, ADInstruments, Oxford, UK).

Afterwards, the tracheal cannula was connected to a respirator (KTR-5 small animal ventilator, Hugo Sachs Elektronik-
Havard Apparatus, March-Hugstetten, Germany), and highly purified synthetic air (Air Liquide, Ludwigshafen, Germany) was used. Tidal volume was adjusted to a normal lift of the thorax with a tidal volume of 6-8 $\mathrm{ml}$ per kilogram of body weight. The ventilator was set to a respiratory rate of $65 / \mathrm{min}$, with a positive end-expiratory pressure of $1-2 \mathrm{cmH}_{2} \mathrm{O}$, and a maximal inspiratory pressure of $25 \mathrm{cmH}_{2} \mathrm{O}$. The MCC-IMS instrument (BreathDiscovery, B \& S Analytik, Dortmund, Germany) was connected to the exhalation line of the respirator as described previously [17].

General anaesthesia was maintained throughout the experiment with pentobarbital administered intravenously every $30 \mathrm{~min}$. Cardiac output and arterial blood gas $(0.2 \mathrm{ml})$ were sampled every $4 \mathrm{~h}$ (ABL800 Basic, Radiometer Willich, Germany).

\section{Experimental protocol}

We evaluated two groups of ten rats each assigned to be given isotonic solution intravenously without glucose (G-) or with glucose $(\mathrm{G}+)$ via a venous catheter in the right jugular vein:

G-: Rats were given sterofundin $\mathrm{ISO}^{\circledR}$ (B. Braun, Melsungen, Germany) at a rate of $1 \mathrm{ml} / 100 \mathrm{~g} / \mathrm{h}$ intravenously.

$\mathrm{G}+$ : Rats were given sterofundin BG-5 ${ }^{\circledR}$ (B. Braun, Melsungen, Germany) including glucose at $50 \mathrm{mg} / \mathrm{ml}$ at a rate of $0.5 \mathrm{ml} / 100 \mathrm{~g} / \mathrm{h}$ intravenously.

\section{MCC-IMS measurements}

MCC-IMS measurements was performed as described elsewhere [17] using a BioScout 2011 (B \& S Analytik, Dortmund, Germany). Ten millilitres of exhaled air (every $20 \mathrm{~min}$ ) was retained in the sample loop before it entered the MCC of the IMS instrument. The retention time in relation to the preseparation of the MCC, the drift time of the ions within the IMS instrument, and the intensity of the analytes were provided by MCC-IMS and were subsequently identified using the BS-MCC/IMS-Analytes database (version 1209) in combination with the program MIMA [21]. VOCs were identified using the program Visual Now 3.1 (B \& S Analytik, Dortmund, Germany). All signals between the thresholds of $1 \mathrm{mV}$ and $5 \mathrm{~V}$ were defined as a peak, and were assigned by their position with drift time and retention time. The concentration of the signal is related to the peak intensity; therefore, a calibration curve with pure substance was realized for acetone as described previously [22]. In the present work, the focus is on identification to achieve a list of interesting analytes. With respect to the major analytes identified, permeation 
standards should be prepared and calibration curves determined within a further step. As performed here, the differentiation is realized using the peak intensity directly without any additional relation to the concentrations of the analytes considered. In the picogram per litre to nanogram per litre concentration range, the realization of proper permeation tubes is rather time-consuming.

\section{Sample preparation for gene expression analysis}

For gene expression analysis, frozen liver tissue (10-15 mg) was homogenized in FastTri buffer (Axon Labortechnik, Kaiserslautern, Germany). Total RNA was isolated according to the manufacturer's instructions, and remaining DNA was digested with DNase I (Fermentas, St Leon-Rot, Germany) and stored at $-80^{\circ} \mathrm{C}$.

\section{Quantitative real-time PCR}

Synthesis of complementary DNA was performed with

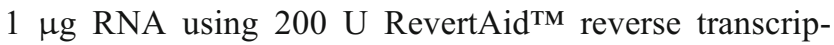
tase (Fermentas, St Leon-Rot, Germany). A complementary DNA equivalent to $10 \mathrm{ng}$ total RNA was applied to the PCR Mastermix with $t 5 \times$ hot start Taq EvaGreen quantitative PCR mix (Axon Labortechnik, Kaiserslautern, Germany) and a concentration of $2.5 \mu \mathrm{M}$ for each primer (unmodified oligos, Eurofins MWG, Ebersberg, Germany). PCR was performed within 40 cycles using a CFX 96 real-time PCR detection system (Bio-Rad, Munich, Germany).The gene expression of succinate dehydrogenase complex, subunit A (SDHA) and that of ribosomal protein S16 (RPS16) were used for normalization. Cycle of quantitation values were determined by non-linear regression fitting of the Richards function [23]. Ratios were calculated by means of the $2^{-\Delta \Delta C_{t}}$ method [24].

\section{Statistical analysis and signal processing}

Mathematical and statistical evaluation was done using SigmaPlot (version 12.5; Systat Software, Erkrath, Germany). Statistical analysis was performed for each VOC at the baseline and every $4 \mathrm{~h}$. On the basis of our previous experience, ten rats per group was sufficient to distinguish clear differences. Data were tested for distribution normality (Kolmogorov-Smirnov test) and analysed using repeatedmeasures analysis of variance (ANOVA) followed by post hoc multiple comparisons with the Holm-Sidak method. When appropriate, a repeated-measures ANOVA on ranks was used. A $p$ value less than 0.05 was considered statistically significant

\section{Results}

Macrohaemodynamic parameters, blood gas analysis,
cardiac output

All rats survived the observation period of $12 \mathrm{~h}$. The baseline mean arterial pressure was similar in both groups, and remained stable throughout the experiment. The heart rate revealed normal baseline values, and was stable in both groups. There were no significant statistical differences for both parameters during the experiment (Fig. 1).

For blood gas analysis, $\mathrm{pH}$, lactate concentration, and haemoglobin concentration presented normal values throughout the experiment. The continuous infusion of glucose led to a significant increase in blood glucose values and cardiac output at $4 \mathrm{~h}$ and thereafter when compared with the values in untreated rats. Furthermore, base excess decreased significantly in the G- group at $12 \mathrm{~h}$, when compared with the $\mathrm{G}+$ group (Table 1).

\section{Multi-capillary-column ion-mobility spectrometry}

Thirty-nine VOCs between the thresholds of $1 \mathrm{mV}$ and $5 \mathrm{~V}$ (set as peak definition) were detected during the experiment. Ten signals displayed significant differences between groups during the observation period, and thus were considered potentially useful VOCs for

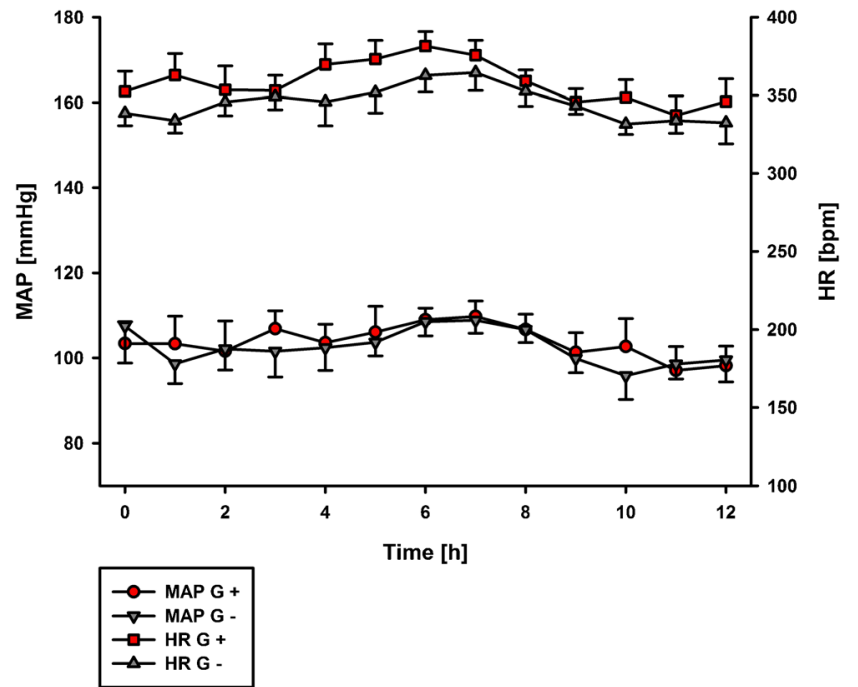

Fig. 1 Measurements of mean arterial pressure $(M A P)$ and heart rate $(H R)$ revealed normal baseline values. During the experiment, MAP and HR remained within normal ranges. There were no significant differences between the treatment groups during the experiment. The data are given as the mean \pm the standard error of the mean (SEM) $(n=$ $10)$. bpm beats per minute, $G$ - without glucose administration, $G^{+}$ glucose administration $(25 \mathrm{mg} / 100 \mathrm{~g} / \mathrm{h})$ 
Table 1 Arterial blood gas analysis and cardiac output

\begin{tabular}{|c|c|c|c|c|}
\hline & $0 \mathrm{~h}$ & $4 \mathrm{~h}$ & $8 \mathrm{~h}$ & $12 \mathrm{~h}$ \\
\hline \multicolumn{5}{|l|}{$\mathrm{pH}$} \\
\hline G- & $7.42(7.28-7.56)$ & $7.43(7.35-7.49)$ & $7.46(7.40-7.54)$ & $7.47(7.44-7.54)$ \\
\hline $\mathrm{G}^{+}$ & $7.44(7.33-7.58)$ & $7.42(7.25-7.48)$ & $7.47(7.39-7.49)$ & $7.46(7.41-7.51)$ \\
\hline \multicolumn{5}{|c|}{ Base excess } \\
\hline G- & $-0.2(-4.4$ to 4.8$)$ & $-2(-4.9$ to 1.1$)$ & $-1.5(-5.3$ to 1.6$)$ & $-4.7^{\#}(-7.9$ to -1.1$)$ \\
\hline $\mathrm{G}^{+}$ & $-2.6(-3.3$ to 3.8$)$ & $-3.4(-7.4$ to 3.5$)$ & $-1.7(-6.1$ to 2.8$)$ & $-1.4(-6.0$ to 1.0$)$ \\
\hline \multicolumn{5}{|c|}{ Lactate } \\
\hline G- & $0.6(0.4-0.8)$ & $0.6(0.3-1.0)$ & $0.6(0.4-0.9)$ & $0.5(0.4-0.8)$ \\
\hline $\mathrm{G}^{+}$ & $0.7(0.4-1.2)$ & $0.7(0.5-1.0)$ & $0.7(0.5-1.0)$ & $0.7(0.6-0.9)$ \\
\hline \multicolumn{5}{|c|}{ Haemoglobin } \\
\hline G- & $14.8(12.5-17.5)$ & $13.5(11.9-15.6)$ & $13.9(12.2-15.4)$ & $12.3(10.1-16.2)$ \\
\hline $\mathrm{G}^{+}$ & $13.7(12.0-15.3)$ & $13.2(10.2-15.5)$ & $13.5(11.5-15.5)$ & $13.6(12.3-15.2)$ \\
\hline \multicolumn{5}{|c|}{ Glucose } \\
\hline G- & $87(72-112)$ & $84 *(66-99)$ & $83 *(64-103)$ & $72 *(55-92)$ \\
\hline $\mathrm{G}^{+}$ & $90(82-99)$ & $104^{\#}(76-137)$ & $105^{\#}(76-134)$ & $108^{\#}(87-149)$ \\
\hline \multicolumn{5}{|c|}{ Cardiac output } \\
\hline G- & $95(73-111)$ & $102 *(89-115)$ & $110 *(69-129)$ & $108 *(89-149)$ \\
\hline $\mathrm{G}^{+}$ & $99(72-136)$ & $173^{\#}(114-248)$ & $155^{\#}(120-195)$ & $142^{\#}(120-172)$ \\
\hline
\end{tabular}

Blood gas analysis revealed normal baseline values of $\mathrm{pH}$, lactate concentration, and haemoglobin concentration throughout the experiment. Glucose values increase significantly in the glucose administration $(G+; 25 \mathrm{mg} / 100 \mathrm{~g} / \mathrm{h})$ group over time when compared with the without glucose administration $(G-)$ group and the baseline. Base excess declined significantly in the G- group after $12 \mathrm{~h}$, when compared with the $\mathrm{G}+$ group. Cardiac output increased significantly in the $\mathrm{G}+$ group at $4 \mathrm{~h}$ and thereafter. Data are given as the mean \pm the $95 \%$ confidence interval $(n=10)$.

${ }^{*} p<0.05$ for G- versus $\mathrm{G}+$.

${ }^{\#} p<0.05$ versus the corresponding baseline

distinguishing among treatments. Nine of them were identified with the BS-MCC/IMS-Analytes database. Yet, one compound remains unknown. All of these compounds are presented in Table 2. In Fig. 2 a typical IMS chromatogram (Fig. 2a) and a typical IMS spectrum (Fig. 2b) are illustrated.

In the G- group, eight peaks presented relatively stable concentrations during the experiment; the levels of the unknown compound ( $p<0.001$ at $2 \mathrm{~h}$ and thereafter) and phenylacetylene $(p<0.001$ at $12 \mathrm{~h})$ decreased significantly when compared with the baseline values. In contrast, only three peaks showed stable profiles in the $\mathrm{G}+$ group during the experiment. Further, seven declined significantly in the $\mathrm{G}+$ group: acetone $(p<0.001$ at $4 \mathrm{~h}$ and thereafter); isoprene, 2-hexanone, phenylacetylene, and the unknown (all $p<0.001$ at $8 \mathrm{~h}$ and thereafter); and $p$-cymol and 2-heptanol (both $p<0.001$ at $8 \mathrm{~h}$ and thereafter) (Table 2, Figs. 3, 4).

Overall, there were significant differences between the Gand $\mathrm{G}+$ groups in the concentration of ten volatile compounds: $p<0.001$ at $4 \mathrm{~h}$ and thereafter for isoprene, cyclohexanone, acetone, $p$-cymol, 2-hexanone, phenylacetylene, and the unknown compound, and $p<0.001$ at $8 \mathrm{~h}$ and thereafter for 1pentanol, 1-propanol, and 2-heptanol (Table 2, Figs. 3, 4).

\section{Glucose treatment and analysis of nonlinear regression}

We chose an infusion rate of $0.5 \mathrm{ml} / 100 \mathrm{~g} / \mathrm{h}$ including $5 \%$ glucose in the $\mathrm{G}+$ group. One gram of glucose implies a calorific value of $16 \mathrm{~kJ}$. During an observation period of $24 \mathrm{~h}$, a rat would receive approximately $200 \mathrm{~kJ} / \mathrm{kg}$, representing a third of the normal basal metabolic rate per day.

Correlation between acetone and blood glucose showed a poor trend towards higher acetone concentrations in exhaled air and decreasing blood glucose values, with a correlation coefficient of $R=0.52$ (Fig. 5a). However, a clear trend towards lower acetone concentrations with the cumulative dose of glucose was noted ( $R=0.88$; Fig. $5 b)$.

\section{Quantitative real-time PCR}

After $12 \mathrm{~h}$, quantitative real-time analysis of glucose 6phosphatase $(p=0.95)$, phosphoenolpyruvate carboxykinase $(p=0.11)$, and cyclic AMP response element binding protein $(p=0.59)$, the central enzymes of gluconeogenesis and glycolysis, in liver tissue, as well as 3-hydroxy-3-methyl-glutaryl-CoA reductase, the ratecontrolling enzyme of the mevalonate pathway, showed 
Table 2 Identification and changes in volatile organic compounds

\begin{tabular}{|c|c|c|c|c|}
\hline & $0 \mathrm{~h}$ & $4 \mathrm{~h}$ & $8 \mathrm{~h}$ & $12 \mathrm{~h}$ \\
\hline \multicolumn{5}{|c|}{ Isoprene } \\
\hline G- & $36.6(14.9-61.1)$ & $36.8 *(19.0-54.7)$ & $36.8^{*}(19.5-53.6)$ & $35.6 *(18.6-53.1)$ \\
\hline $\mathrm{G}^{+}$ & $28.0(13.4-46.2)$ & $14.9(8.2-29.3)$ & $12.8^{\#}(9.0-18.8)$ & $10.7^{\#}(6.5-15.8)$ \\
\hline \multicolumn{5}{|c|}{ Cyclohexanone } \\
\hline G- & $30.9(7.7-49.4)$ & $42.2 *(8.1-76.8)$ & $36.2 *(9.9-68.4)$ & $32.5 *(8.7-74.6)$ \\
\hline $\mathrm{G}^{+}$ & $23.6(11.7-37.2)$ & $17.5(12.0-24.9)$ & $15.8(10.7-22.9)$ & $13.8(9.9-18.9)$ \\
\hline \multicolumn{5}{|c|}{ 1-Pentanol } \\
\hline G- & $22.3(9.7-46.1)$ & $26.8(13.7-46.7)$ & $31.7 *(17.1-60.2)$ & $33.0 *(15.3-68.1)$ \\
\hline $\mathrm{G}^{+}$ & $14.5(11.3-27.7)$ & $15.1(6.3-40.8)$ & $12.8(5.8-25.4)$ & $12.0(6.5-25.4)$ \\
\hline \multicolumn{5}{|c|}{ Acetone } \\
\hline G- & $381(135-828)$ & $534 *(184-855)$ & $527 *(246-861)$ & $491 *(136-852)$ \\
\hline $\mathrm{G}^{+}$ & $215(31.9-477)$ & $76.0^{\#}(26.8-183)$ & $57.1^{\#}(25.2-134)$ & $37.4^{\#}(22.4-55.2)$ \\
\hline \multicolumn{5}{|c|}{ p-Cymol } \\
\hline G- & $10.5(8.3-14.7)$ & $12.4 *(10.5-16.1)$ & $12.5^{*}(9.7-16.5)$ & $11.6^{*}(7.7-16.7)$ \\
\hline $\mathrm{G}^{+}$ & $9.8(7.0-12.9)$ & $8.1(5.7-11.5)$ & $7.5(5.1-11.3)$ & $6.5^{\#}(4.4-9.7)$ \\
\hline \multicolumn{5}{|c|}{ 1-Propanol } \\
\hline G- & $15.9(1.9-39.9)$ & $21.9(10.0-39.6)$ & $25.5^{*}(11.3-56.6)$ & $26.2 *(9.5-59.4)$ \\
\hline $\mathrm{G}^{+}$ & $11.9(6.0-18.5)$ & $9.6(5.0-17.5)$ & $9.6(5.4-21.3)$ & $9.9(4.1-12.9)$ \\
\hline \multicolumn{5}{|c|}{ 2-Hexanone } \\
\hline G- & $22.5(15.3-34.4)$ & $22.8 *(19.4-29.9)$ & $22.2 *(19.0-30.7)$ & $22.9 *(15.9-38.5)$ \\
\hline $\mathrm{G}^{+}$ & $23.7(15.8-41.3)$ & $16.2(8.9-33.2)$ & $14.3^{\#}(8.5-19.5)$ & $12.1^{\#}(9.2-16.4)$ \\
\hline \multicolumn{5}{|c|}{ 2-Heptanol } \\
\hline G- & $6.9(2.7-14.6)$ & $7.5(2.2-12.6)$ & $7.0 *(3.4-12.1)$ & $6.3 *(2.5-9.3)$ \\
\hline $\mathrm{G}^{+}$ & $6.4(2.7-13.1)$ & $4.5(2.3-10.3)$ & $3.7(2.4-5.5)$ & $3.1^{\#}(2.1-4.8)$ \\
\hline \multicolumn{5}{|c|}{ Phenylacetylene } \\
\hline G- & $14.2(6.5-21.7)$ & $13.4 *(5.6-18.8)$ & $13.9 *(10.5-18.1)$ & $11.4^{*, \#}(5.6-20.1)$ \\
\hline $\mathrm{G}^{+}$ & $14.0(5.6-23.5)$ & $8.2(4.1-22.6)$ & $6.8^{\#}(4.3-13.3)$ & $5.8^{\#}(4.5-7.5)$ \\
\hline \multicolumn{5}{|c|}{ Unknown } \\
\hline G- & $436(163-569)$ & $683^{*, \#}(496-862)$ & $679^{*, \#}(558-866)$ & $633^{*, \#}(406-866)$ \\
\hline $\mathrm{G}^{+}$ & $323(109-532)$ & $144(50.2-266)$ & $70.4^{\#}(30.6-135)$ & $52.4^{\#}(30.0-90.1)$ \\
\hline
\end{tabular}

Ten volatile organic compounds with significant changes of peak intensities were found during the observation period. Nine of them were identified, one remains unknown. Data are given as the mean \pm the $95 \%$ confidence interval $(n=10)$.

${ }^{*} p<0.05$ for no glucose administration $(G-)$ versus glucose administration at $25 \mathrm{mg} / 100 \mathrm{~g} / \mathrm{h}(G+)$.

${ }^{\#} p<0.05$ versus the corresponding baseline.

no differences between groups $(p=0.22$; data not shown).

\section{Discussion}

Metabolic profiling of VOCs is becoming increasingly popular in breath research. It is recognized that a single VOC or the combination of different VOCs will most likely indicate particular diseases and metabolic conditions.

The present study investigated rats after $12 \mathrm{~h}$ of fasting assigned to infusion with or without glucose during the following $12 \mathrm{~h}$. Almost ten VOCs showed differences between groups during the experiment, thus confirming the changes in rat metabolism caused by glucose infusion as seen in blood glucose levels. The dose of $5 \%$ glucose was especially chosen to maintain a third of the normal basal metabolic rate of approximately $600 \mathrm{~kJ} / \mathrm{kg}$ under life conditions [25]. Because general anaesthesia reduces the global metabolic rate, a higher infusion rate led to an overdose and hyperglycaemia [26, 27]. Hence, excessive amounts of glucose in the blood led to a wide variety of serious metabolic disorders - for example, ketoacidosis, dehydration, due osmotic diuresis, and impairment of consciousness with hemodynamic decompensation during anaesthesia. Further, hyperglycaemia caused a 'fruity' 

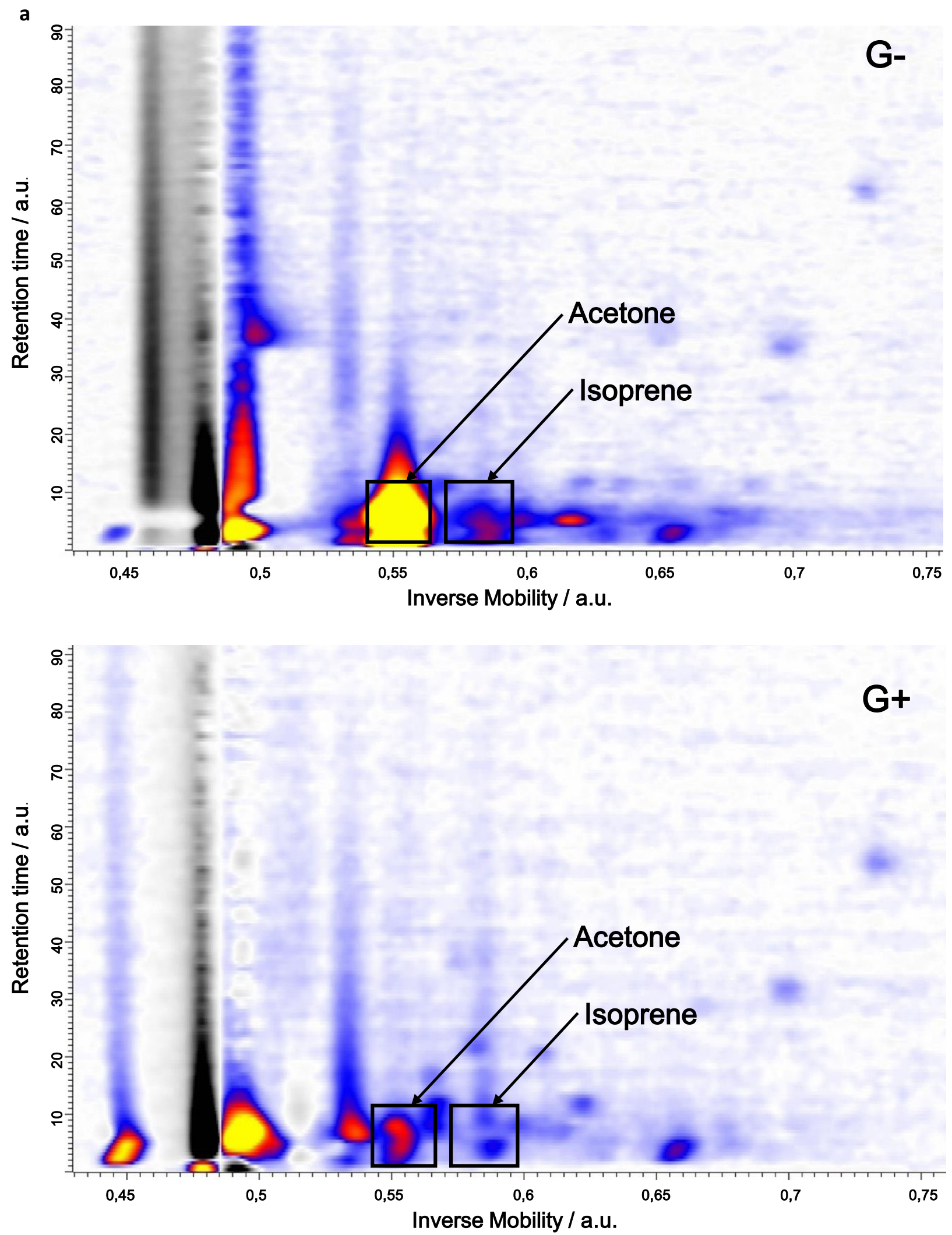

Fig. 2 a A multicapillary column ion-mobility spectrometry (MCCIMS) chromatogram and $\mathbf{b}$ the MCC-IMS spectrum for individual rats after $12 \mathrm{~h}$. Acetone and isoprene were labelled by their position using the inverse reduced mobility (axis of abscissa; $1 / K_{0}$ ) and the retention time (axis of ordinates; retention time) as well as the peak expansion. $G$ without glucose administration, $G^{+}$glucose administration $(25 \mathrm{mg} /$ $100 \mathrm{~g} / \mathrm{h})$ 

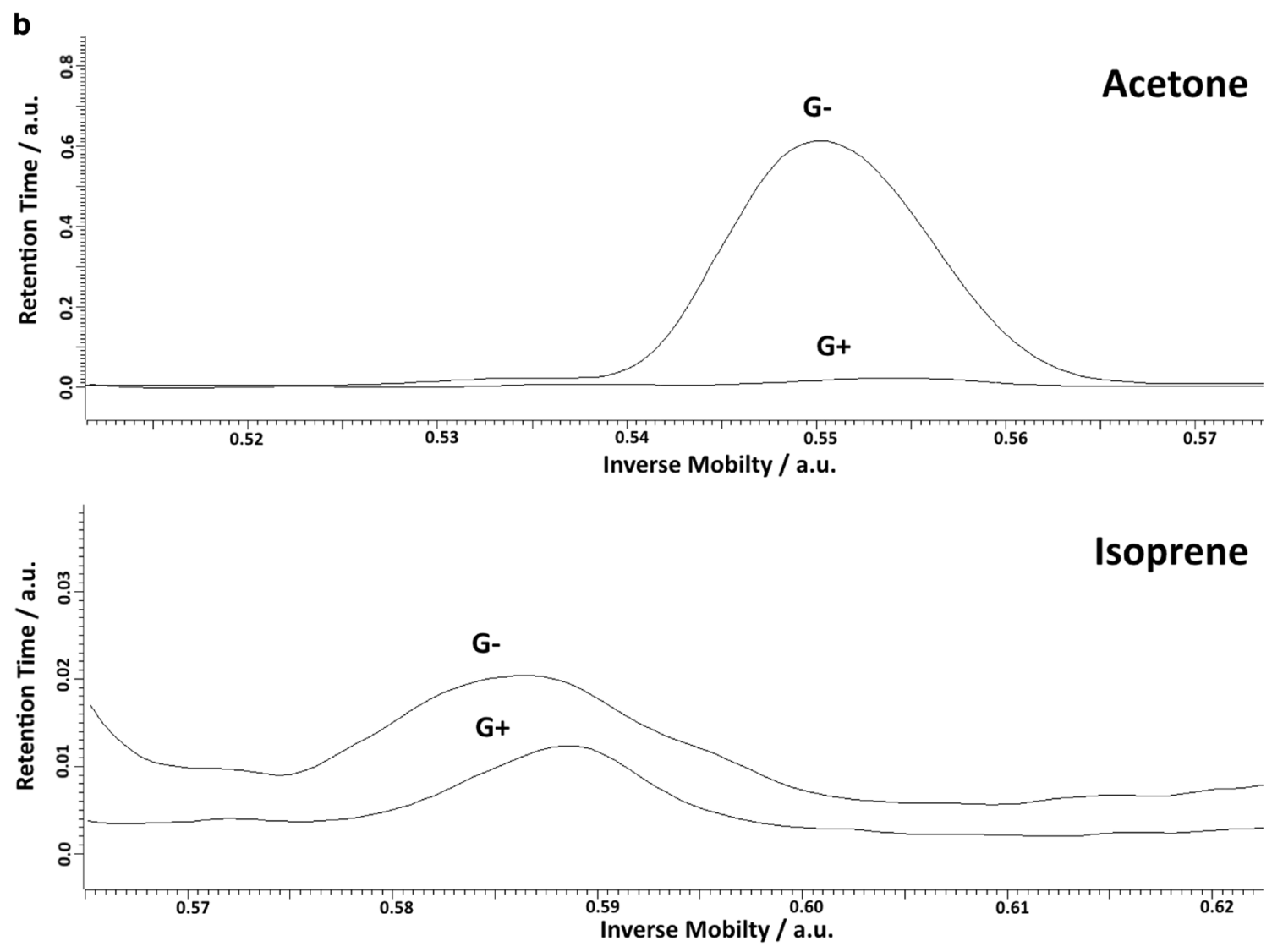

Fig. 2 (continued)

smell of breath that seriously affects the chemical compositions in exhaled air.

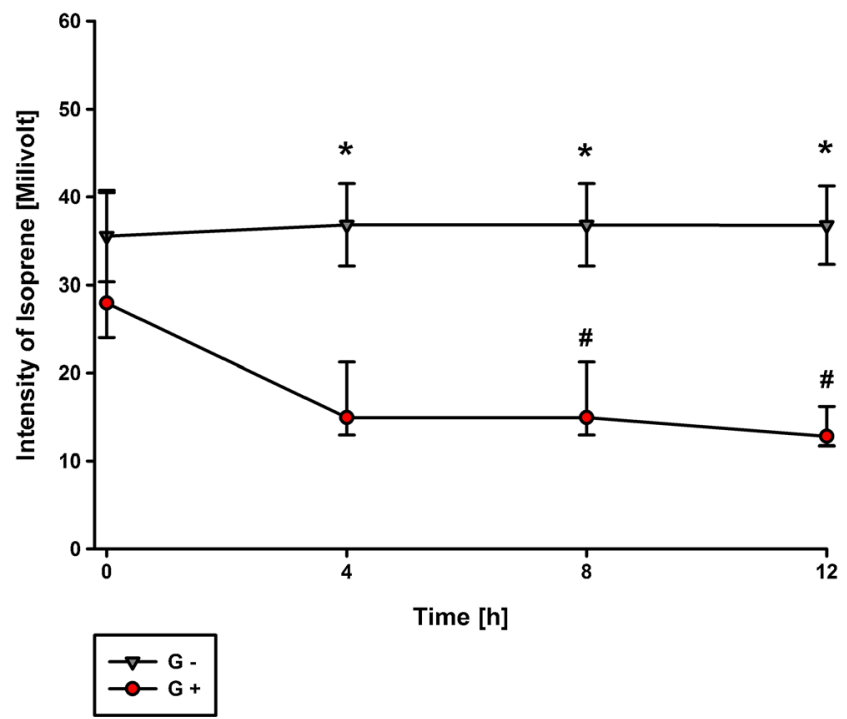

Fig. 3 Peak course of isoprene. Infusion without glucose $(G-)$ resulted in stable signal strength during the experiment. For glucose treatment $\left(G^{+}\right.$; $25 \mathrm{mg} / 100 \mathrm{~g} / \mathrm{h}$ ), isoprene concentrations declined significantly during the observation period. Asterisk $p<0.05$ for $\mathrm{G}-$ versus $\mathrm{G}+$, pound sign $p<$ 0.05 versus the corresponding baseline. Data are given as the mean \pm $\operatorname{SEM}(n=10)$
Our findings are well in line with preceding reports demonstrating changes in VOCs during diet and fasting [18 26].

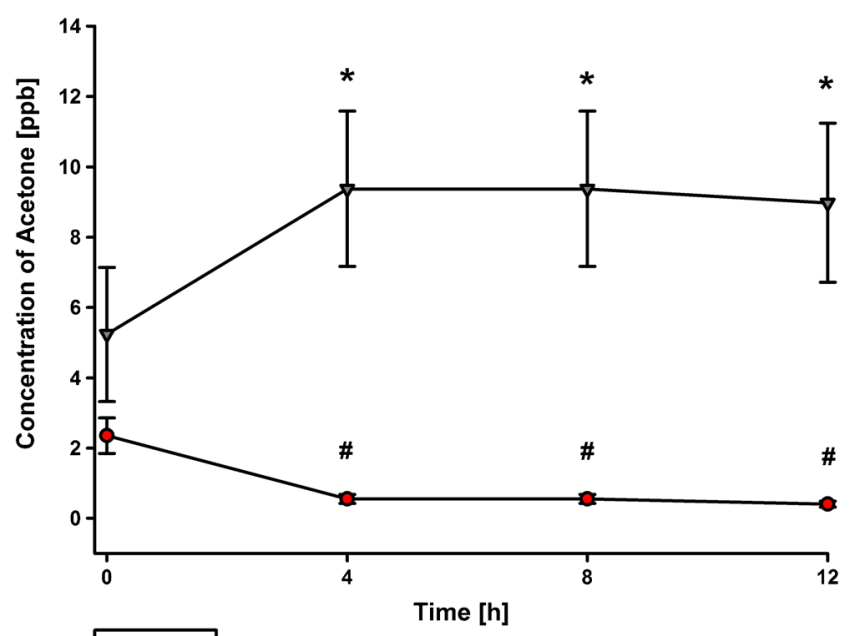

Fig. 4 Peak course of acetone. Withholding of glucose $(G$-) results in a significant increase of acetone concentration. For glucose treatment $(G+$; $25 \mathrm{mg} / 100 \mathrm{~g} / \mathrm{h}$ ), the peak intensity declined during the experiment. Differences between the groups became significant at $4 \mathrm{~h}$ and thereafter. Asterisk $p<0.05$ for $\mathrm{G}-$ versus $\mathrm{G}+$, pound sign $p<0.05$ versus the corresponding baseline. Data are given as the mean $\pm \operatorname{SEM}(n=10)$ 

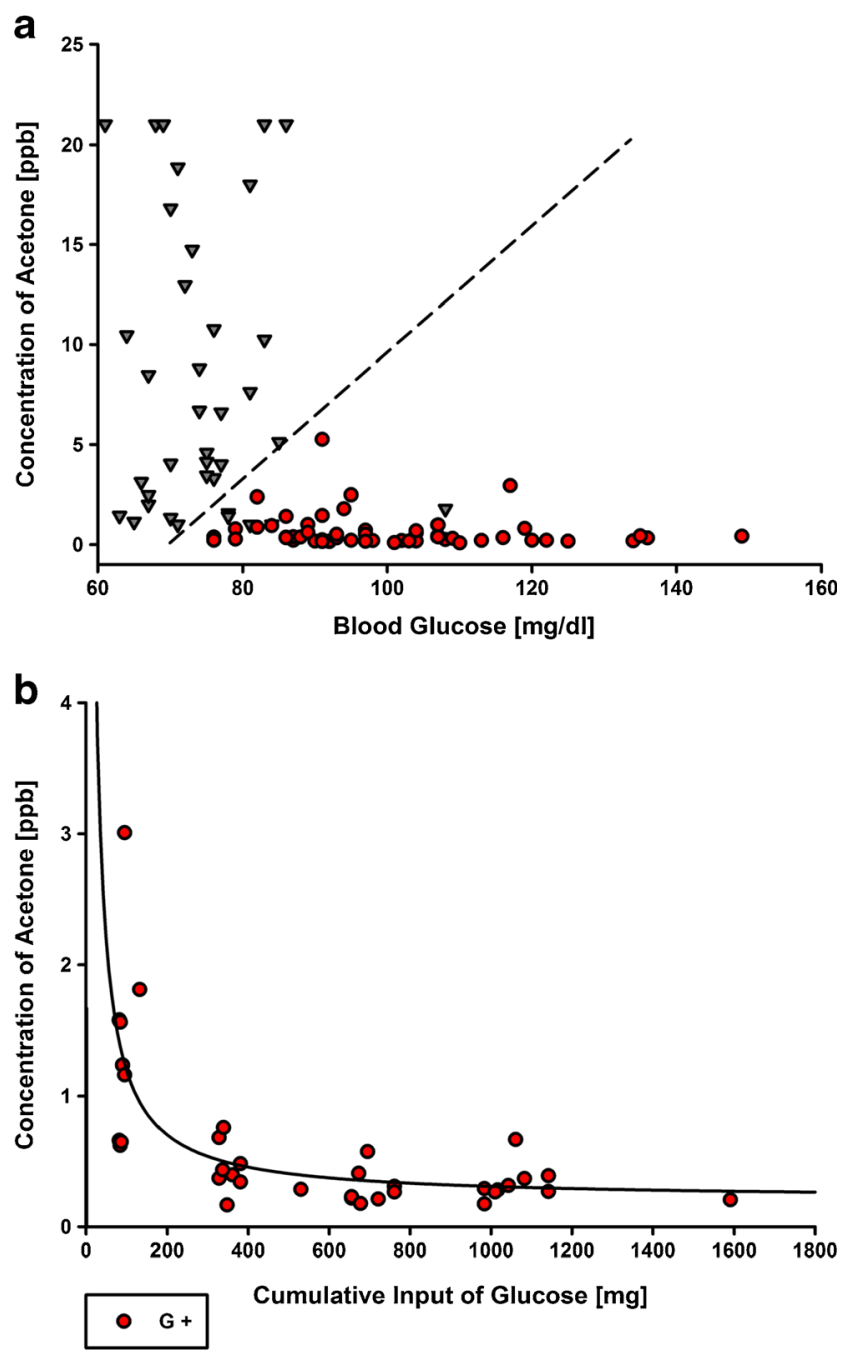

Fig. 5 Correlation between acetone concentration and blood glucose level (a) and between acetone concentration and cumulative input of glucose (b). a The correlation between the absolute acetone concentration in parts per billion with a correlation coefficient of nonlinear regression (exponential decay, single, three parameter) was $R=$ 0.52; however, there is a poor trend towards lower acetone concentrations with increasing blood glucose levels. The dotted line (with the function $y=0.28 x-19.6$ ) indicates the possibility to distinguish between animals with and without glucose treatment. b The correlation coefficient of nonlinear regression (polynomial; inverse third order) was $R=0.82$. There is a clear trend towards lower acetone concentrations with the cumulative input of glucose adjusted per $100 \mathrm{~g}$ body weight. $G+$ glucose administration $(25 \mathrm{mg} / 100 \mathrm{~g} / \mathrm{h})$

Statheropoulos et al. [28] investigated fasting monks, who showed "positive alveolar gradients" for acetone, phenol, DL-limonene, 2-pentanone, isoprene, and acetaldehyde after 3 days of fasting. Another study showed that diet and nutritional status influence the levels of acetone, methanol, ethanol, and ammonia in breath [18].

The origin and the metabolic significance of most VOCs are still unknown. The blood-borne ketone acetone, an organic compound produced in hepatocytes from humans and animals by decarboxylation of acetoacetate and dehydrogenation of 2- propanol [29], has been thoroughly investigated. It is mostly present in blood, urine, and expired air. Fasting and diabetes led to an increase of acetone concentration. The mechanism of acetone production is likely the result of lipid mobilization $[23,24]$. Hence, acetone is of obvious interest for breath analysis. Much effort has been done to study acetone in exhaled breath as a marker of blood glucose and glycaemic conditions. Consequently, breath acetone concentration could distinguish between patients with diabetes and healthy patients. Greiter et al. [30] identified eight VOCs to distinguish between patients with insulin-treated type 2 diabetes and healthy patients. Other authors showed a linear relationship between haemoglobin $\mathrm{A}_{1 \mathrm{c}}$, breath acetone, and blood glucose in type 1 diabetes, which is contrary to expectations based on normal physiological conditions [31]. However, we found no significant differences in the expression of the central enzymes of gluconeogenesis and glycolysis between groups which could help to differentiate between VOC changes and metabolic conditions. Under certain circumstances, this might be attributed to the low-dose glucose treatment or the time of fasting.

As mentioned in the previous section, some studies found different correlations between blood glucose and exhaled breath, with a regression coefficient range from 0.08 to 0.98 [32-40]. Yet, in our study we found a negative correlation towards higher acetone concentrations when blood glucose concentrations declined, with a regression coefficient of only 0.52 . Even more interesting is that our findings show a clearer trend, with a correlation of 0.82 when the cumulative dose of glucose was correlated with absolute acetone concentration.

One reason for the wide regression coefficient range could be the inhomogeneous target groups with different conditions of measurement used in most studies. Under these circumstances, acetone as a substrate of ketogenesis is influenced by many physiological and pathophysiological conditions which may influence the affected breath acetone concentration, including lipolysis, breath pattern, dead space ventilation, cardiac output, fasting, and especially diabetes or insulin therapy [41-43]. With particular focus on study design, some of these factors cannot be controlled - that is, with regard to difficult comparableness. Therefore, most of the published studies came to the conclusion that there is a correlation between breath acetone, and blood acetone or ketone concentration, but single breath measurements of acetone do not provide a good measurement of blood glucose levels. It is too early to draw a general conclusion on the relationship between a breath acetone level and a blood glucose level [41-46]. Acetone levels were generally higher in diabetic patients, but large interindividual variability requires caution when the acetone breath test is used $[42,43]$.

We speculate that the different findings in our study, with a negative correlation coefficient between breath acetone and blood glucose, may be caused by the glucose injection in contrast to native blood glucose conditions. Moreover, not 
all findings in rodent models can be compared with human conditions. But to our knowledge, there are only a few differences between human and rats regarding physiological changes after glucose treatment and fasting. Accordingly, a further important limitation of the techniques is that none of them used continuous monitoring of exhaled breath as seen in our study.

Nevertheless, this forcefully illustrates that exhaled acetone might be a useful biomarker for glycaemic control. For this reason, the production of analysis tools which will be adequate for acetone analysis in exhaled air is of great interest $[31,33,47-49]$. Problems with these devices were the low sensitivity and the failure under high humidity $[31,33]$. In this investigation, we used an IMS instrument coupled with an MCC to ensure effective separation of humidity.

Another VOC to be pointed out is isoprene, the major hydrocarbon found in human breath, with high interindividual variability [50]. Isoprene is a substrate in the mevalonate pathway of cholesterol synthesis, whereas acetaldehyde is probably produced by oxidation of endogenous ethanol [51]. In exhaled air it shows a correlation with cholesterol biosynthesis, but not with blood glucose [33]. High mixed venous blood concentrations also suggest a peripheral origin - for instance, from muscular cells [52]. In the present study, isoprene concentration declined over time in the $\mathrm{G}+$ group when compared with the G- group. Interestingly, a past study reported that the concentration of isoprene does not appear to be influenced by gender, diet, or fasting in humans, but rats can be manipulated to produce more or less isoprene by dietary means [50]. Karl et al. $[53,54]$ found that the large variability between individuals is related to a variation in the heart rate and exhalation rate together with differences in the endogenous isoprene production. In our study, the observed alteration in isoprene concentration is unlikely to be the result of changes in heart rate or blood pressure, but seems more likely to be due to changes in endogenous production.

It should be noted that cardiac output increased and isoprene concentration decreased over time in $\mathrm{G}+$ rats during the experiment. Other studies reported an early and short-term rise of isoprene concentration in exhaled breath when cardiac output increased [54, 55]. Recent investigations support our finding that changes in blood glucose and insulin concentrations may influence the heart rate, cardiac output, and blood pressure $[54,56]$.

Our current results emphasize the importance of stable metabolic conditions during breath analysis. Especially for longterm measurement, fasting and the withholding of glucose could contribute to a false interpretation of volatile metabolites in exhaled air. The results of our study showed ten VOCs with significant differences between groups. Only isoprene and acetone could be assigned to their metabolism. The origin of the further eight VOCs remains unknown, and greater emphasis is needed to evaluate plausible mechanisms for changes in these potential biomarkers.
Acknowledgments This study was solely funded by departmental funds of the Department of Anaesthesiology, Intensive Care and Pain Therapy, Saarland University Medical Center. The authors thank Karen Schneider for revising this work linguistically.

Conflict of interest The authors declare that they have no conflict of interest.

\section{References}

1. Fink T, Wolf A, Maurer F, Albrecht FW, Heim N, Wolf B, Hauschild AC, Bodeker B, Baumbach JI, Volk T, Sessler DI, Kreuer S (2014) Volatile organic compounds during inflammation and sepsis in rats: a potential breath test using ion-mobility spectrometry. Anesthesiology. doi:10.1097/ALN.0000000000000420

2. Spanel P, Smith D (2011) Volatile compounds in health and disease. Curr Opin Clin Nutr Metab Care 14(5):455-460. doi:10.1097/ MCO.0b013e3283490280

3. Eiceman GA, Stone JA (2004) Ion mobility spectrometers in national defence. Anal Chem 76(21):390A-397A

4. Baumbach JI, Eiceman GA (1999) Ion mobility spectrometry: arriving on site and moving beyond a low profile. Appl Spectrosc 53(9):338A-355A

5. Eiceman GA, Blyth DA, Shoff DB, Snyder AP (1990) Screening of solid commercial pharmaceuticals using ion mobility spectrometry. Anal Chem 62(14):1374-1379

6. Baumbach JI (2006) Process analysis using ion mobility spectrometry. Anal Bioanal Chem 384(5):1059-1070. doi:10.1007/s00216005-3397-8

7. Baumbach JI (2009) Ion mobility spectrometry coupled with multicapillary columns for metabolic profiling of human breath. J Breath Res 3(3):034001. doi:10.1088/1752-7155/3/3/034001

8. Westhoff M, Freitag PLL, Ruzsanyi V, Bader S, Urfer W, Baumbach JI (2005) Ion mobility spectrometry: A new method for the detection of lung cancer and airway infection in exhaled air? First results of a pilot study. Chest 128(4):155s

9. Westhoff M, Litterst P, Maddula S, Bödeker B, Baumbach JI (2011) Statistical and bioinformatical methods to differentiate chronic obstructive pulmonary disease (COPD) including lung cancer from healthy control by breath analysis using ion mobility spectrometry. Int J Ion Mobil Spectrom 14(4):139-149. doi:10.1007/s12127-0110081-x

10. de Gennaro G, Dragonieri S, Longobardi F, Musti M, Stallone G, Trizio L, Tutino M (2010) Chemical characterization of exhaled breath to differentiate between patients with malignant plueral mesothelioma from subjects with similar professional asbestos exposure. Anal Bioanal Chem 398(7-8):3043-3050. doi:10.1007/ s00216-010-4238-y

11. Guaman AV, Carreras A, Calvo D, Agudo I, Navajas D, Pardo A, Marco S, Farre R (2012) Rapid detection of sepsis in rats through volatile organic compounds in breath. J Chromatogr B 881-882: 76-82. doi:10.1016/j.jchromb.2011.12.001

12. Maddula S, Blank LM, Schmid A, Baumbach JI (2009) Detection of volatile metabolites of Escherichia coli by multi capillary column coupled ion mobility spectrometry. Anal Bioanal Chem 394(3): 791-800. doi:10.1007/s00216-009-2758-0

13. Dummer JF, Storer MK, Hu WP, Swanney MP, Milne GJ, Frampton CM, Scotter JM, Prisk GK, Epton MJ (2010) Accurate, reproducible measurement of acetone concentration in breath using selected ion flow tube-mass spectrometry. J Breath Res 4(4): 046001. doi:10.1088/1752-7155/4/4/046001

14. Endre ZH, Pickering JW, Storer MK, Hu WP, Moorhead KT, Allardyce R, McGregor DO, Scotter JM (2011) Breath ammonia 
and trimethylamine allow real-time monitoring of haemodialysis efficacy. Physiol Meas 32(1):115-130. doi:10.1088/0967-3334/ 32/1/008

15. Carroll W, Lenney W, Wang T, Spanel P, Alcock A, Smith D (2005) Detection of volatile compounds emitted by Pseudomonas aeruginosa using selected ion flow tube mass spectrometry. Pediatr Pulmonol 39(5):452-456. doi:10.1002/ppul.20170

16. Enderby B, Smith D, Carroll W, Lenney W (2009) Hydrogen cyanide as a biomarker for Pseudomonas aeruginosa in the breath of children with cystic fibrosis. Pediatr Pulmonol 44(2):142-147. doi: 10.1002/ppul.20963

17. Wolf A, Baumbach JI, Kleber A, Maurer F, Maddula S, Favrod P, Jang M, Fink T, Volk T, Kreuer S (2014) Multi-capillary columnion mobility spectrometer (MCC-IMS) breath analysis in ventilated rats: a model with the feasibility of long-term measurements. J Breath Res 8(1):016006. doi:10.1088/1752-7155/8/1/016006

18. Smith D, Spanel P, Davies S (1999) Trace gases in breath of healthy volunteers when fasting and after a protein-calorie meal: a preliminary study. J Appl Physiol 87(5):1584-1588

19. Spanel P, Dryahina K, Rejskova A, Chippendale TW, Smith D (2011) Breath acetone concentration; biological variability and the influence of diet. Physiol Meas 32(8):N23-N31. doi:10.1088/09673334/32/8/N01

20. Turner C, Spanel P, Smith D (2006) A longitudinal study of ammonia, acetone and propanol in the exhaled breath of 30 subjects using selected ion flow tube mass spectrometry, SIFT-MS. Physiol Meas 27(4):321-337. doi:10.1088/0967-3334/27/4/001

21. Maurer F, Hauschild AC, Eisinger K, Baumbach J, Mayor A, Baumbach JI (2014) MIMA - a software for analyte identification in MCC/IMS chromatograms by mapping accompanying GC/MS measurements. Int J Ion Mobil Spectrom 17(2):95-101. doi:10. 1007/s12127-014-0149-5

22. Vautz W, Schmäh M (2009) HovaCAL ${ }^{\circledR}$ —a generator for multicomponent humid calibration gases. Int J Ion Mobil Spectrom 12(4):139-147. doi:10.1007/s12127-009-0030-0

23. Jones AW (1987) Breath-acetone concentrations in fasting healthy men: response of infrared breath-alcohol analyzers. J Anal Toxicol 11(2):67-69

24. Kundu SK, Bruzek JA, Nair R, Judilla AM (1993) Breath acetone analyzer: diagnostic tool to monitor dietary fat loss. Clin Chem 39(1):87-92

25. Subcommittee on Laboratory Animal Nutrition, Committee on Animal Nutrition, Board on Agriculture, National Research Council (1995) Nutrient requirements of laboratory animals, 4th revised edition. National Academy Press, Washington

26. Oshima T, Karasawa F, Okazaki Y, Wada H, Satoh T (2003) Effects of sevoflurane on cerebral blood flow and cerebral metabolic rate of oxygen in human beings: a comparison with isoflurane. Eur $\mathrm{J}$ Anaesthesiol 20(7):543-547

27. O'Connell MT, Seal A, Nortje J, Al-Rawi PG, Coles JP, Fryer TD, Menon DK, Pickard JD, Hutchinson PJ (2005) Glucose metabolism in traumatic brain injury: a combined microdialysis and [18F]-2fluoro-2-deoxy-D-glucose-positron emission tomography (FDGPET) study. Acta Neurochir Suppl 95:165-168

28. Statheropoulos M, Agapiou A, Georgiadou A (2006) Analysis of expired air of fasting male monks at Mount Athos. J Chromatogr B 832(2):274-279. doi:10.1016/j.jchromb.2006.01.017

29. Kalapos MP (2003) On the mammalian acetone metabolism: from chemistry to clinical implications. Biochim Biophys Acta 1621(2): 122-139

30. Greiter MB, Keck L, Siegmund T, Hoeschen C, Oeh U, Paretzke HG (2010) Differences in exhaled gas profiles between patients with type 2 diabetes and healthy controls. Diabetes Technol Ther 12(6):455-463. doi:10.1089/dia.2009.0181

31. Denzer W, Hancock G, Islam M, Langley CE, Peverall R, Ritchie GA, Taylor D (2011) Trace species detection in the near infrared using Fourier transform broadband cavity enhanced absorption spectroscopy: initial studies on potential breath analytes. Analyst 136(4):801-806. doi:10.1039/c0an00462f

32. Leopold JH, van Hooijdonk RT, Sterk PJ, Abu-Hanna A, Schultz MJ, Bos L (2014) Glucose prediction by analysis of exhaled metabolites - a systematic review. BMC Anesthesiol 14:46. doi:10. 1186/1471-2253-14-46

33. Righettoni M, Schmid A, Amann A, Pratsinis SE (2013) Correlations between blood glucose and breath components from portable gas sensors and PTR-TOF-MS. J Breath Res 7(3):037110. doi:10.1088/1752-7155/7/3/037110

34. Storer M, Dummer J, Lunt H, Scotter J, McCartin F, Cook J, Swanney M, Kendall D, Logan F, Epton M (2011) Measurement of breath acetone concentrations by selected ion flow tube mass spectrometry in type 2 diabetes. J Breath Res 5(4):046011. doi: 10.1088/1752-7155/5/4/046011

35. Minh TD, Oliver SR, Ngo J, Flores R, Midyett J, Meinardi S, Carlson MK, Rowland FS, Blake DR, Galassetti PR (2011) Noninvasive measurement of plasma glucose from exhaled breath in healthy and type 1 diabetic subjects. Am J Physiol Endocrinol Metab 300(6):E1166-E1175. doi:10.1152/ajpendo.00634.2010

36. Turner C, Walton C, Hoashi S, Evans M (2009) Breath acetone concentration decreases with blood glucose concentration in type I diabetes mellitus patients during hypoglycaemic clamps. J Breath Res 3(4):046004. doi:10.1088/1752-7155/3/4/046004

37. Lee J, Ngo J, Blake D, Meinardi S, Pontello AM, Newcomb R, Galassetti PR (2009) Improved predictive models for plasma glucose estimation from multi-linear regression analysis of exhaled volatile organic compounds. J Appl Physiol 107(1):155-160. doi: 10.1152/japplphysiol.91657.2008

38. Fritsch T, van Herpen M, von Basum G, Hering P, Murtz M (2008) Is exhaled carbon monoxide level associated with blood glucose level? A comparison of two breath analyzing methods. J Biomed Opt 13(3):034012. doi:10.1117/1.2937215

39. Novak BJ, Blake DR, Meinardi S, Rowland FS, Pontello A, Cooper DM, Galassetti PR (2007) Exhaled methyl nitrate as a noninvasive marker of hyperglycemia in type 1 diabetes. Proc Natl Acad Sci U S A 104(40):15613-15618. doi:10.1073/pnas.0706533104

40. Duarte NC, Becker SA, Jamshidi N, Thiele I, Mo ML, Vo TD, Srivas R, Palsson BO (2007) Global reconstruction of the human metabolic network based on genomic and bibliomic data. Proc Natl Acad Sci USA 104(6):1777-1782. doi:10.1073/pnas.0610772104

41. Galassetti PR, Novak B, Nemet D, Rose-Gottron C, Cooper DM, Meinardi S, Newcomb R, Zaldivar F, Blake DR (2005) Breath ethanol and acetone as indicators of serum glucose levels: an initial report. Diabetes Technol Ther 7(1):115-123. doi:10.1089/dia.2005. 7.115

42. Ghimenti S, Tabucchi S, Lomonaco T, Di Francesco F, Fuoco R, Onor M, Lenzi S, Trivella MG (2013) Monitoring breath during oral glucose tolerance tests. J Breath Res 7(1):017115. doi:10.1088/ $1752-7155 / 7 / 1 / 017115$

43. Wang Z, Wang C (2013) Is breath acetone a biomarker of diabetes? A historical review on breath acetone measurements. J Breath Res 7(3):037109. doi:10.1088/1752-7155/7/3/037109

44. Walton C, Patel M, Pitts D, Knight P, Hoashi S, Evans M, Turner C (2014) The use of a portable breath analysis device in monitoring type 1 diabetes patients in a hypoglycaemic clamp: validation with SIFT-MS data. J Breath Res 8(3):037108. doi:10.1088/1752-7155/ 8/3/037108

45. Sturney SC, Storer MK, Shaw GM, Shaw DE, Epton MJ (2013) Off-line breath acetone analysis in critical illness. J Breath Res 7(3): 037102. doi:10.1088/1752-7155/7/3/037102

46. Blaikie TP, Edge JA, Hancock G, Lunn D, Megson C, Peverall R, Richmond G, Ritchie GA, Taylor D (2014) Comparison of breath gases, including acetone, with blood glucose and blood ketones in 
children and adolescents with type 1 diabetes. J Breath Res 8(4): 046010. doi: $10.1088 / 1752-7155 / 8 / 4 / 046010$

47. Phillips M, Herrera J, Krishnan S, Zain M, Greenberg J, Cataneo RN (1999) Variation in volatile organic compounds in the breath of normal humans. J Chromatogr B 729(1-2):75-88

48. Spanel P, Davies S, Smith D (1998) Quantification of ammonia in human breath by the selected ion flow tube analytical method using $\mathrm{H} 30+$ and $02+$ precursor ions. Rapid Commun Mass Spectrom 12(12):763-766. doi:10.1002/(SICI)1097-0231(19980630) 12:12<763::AID-RCM229>3.0.CO;2-S

49. Ruzsanyi V, Baumbach JI, Sielemann S, Litterst P, Westhoff M, Freitag L (2005) Detection of human metabolites using multicapillary columns coupled to ion mobility spectrometers. J Chromatogr A 1084(1-2):145-151

50. Gelmont D, Stein RA, Mead JF (1981) Isoprene-the main hydrocarbon in human breath. Biochem Biophys Res Commun 99(4): $1456-1460$

51. Phillips M, Greenberg J, Awad J (1994) Metabolic and environmental origins of volatile organic compounds in breath. J Clin Pathol 47(11):1052-1053
52. Miekisch W, Schubert JK, Vagts DA, Geiger K (2001) Analysis of volatile disease markers in blood. Clin Chem 47(6):1053-1060

53. Karl T, Prazeller P, Mayr D, Jordan A, Rieder J, Fall R, Lindinger W (2001) Human breath isoprene and its relation to blood cholesterol levels: new measurements and modeling. J Appl Physiol 91(2): $762-770$

54. King J, Kupferthaler A, Unterkofler K, Koc H, Teschl S, Teschl G, Miekisch W, Schubert J, Hinterhuber H, Amann A (2009) Isoprene and acetone concentration profiles during exercise on an ergometer. J Breath Res 3(2):027006. doi:10. 1088/1752-7155/3/2/027006

55. King J, Mochalski P, Kupferthaler A, Unterkofler K, Koc H, Filipiak W, Teschl S, Hinterhuber H, Amann A (2010) Dynamic profiles of volatile organic compounds in exhaled breath as determined by a coupled PTR-MS/GC-MS study. Physiol Meas 31(9): 1169-1184. doi:10.1088/0967-3334/31/9/008

56. Hlebowicz J, Lindstedt S, Bjorgell O, Dencker M (2011) The effect of endogenously released glucose, insulin, glucagon-like peptide 1 , ghrelin on cardiac output, heart rate, stroke volume, and blood pressure. Cardiovasc Ultrasound 9:43. doi:10.1186/1476-7120-9-43 